\title{
DÉBITO PRIMAL: UN NUEVO CONCEPTO EN EL ÁMBITO DEL DERECHO REPRODUCTIVO DE LAS MUJERES
}

\section{PRIMAL DEBT: A NEW CONCEPT IN THE FIELD OF WOMEM REPRODUCTIVE RIGHTS}

\author{
Gabriela Castro-Domínguez ${ }^{1 * \mathbb{D}}$.
}

1. Centro de Especialización Judicial del Poder Judicial del Estado de Tabasco, México.gabrielacprivado@gmail.com

* Autor de correspondencia: Gabriela Castro-Domínguez, correo electrónico: gabrielacprivado@gmail.com

\section{RESUMEN}

En este artículo se introduce el concepto de débito primal en el ámbito del derecho reproductivo de las mujeres. Tal concepto se desarrolla a partir del análisis crítico de las relaciones de simbiosis entre patriarcado y capitalismo y el modo como se involucran históricamente en perjuicio y explotación económica de las mujeres mediante su natural capacidad reproductiva. Sin embargo, es un hecho biológico incuestionable que las mujeres constituyen la fuente primaria y única hacia la continua generación del capital humano; principal factor productivo desde siempre utilizado para la construcción de toda la riqueza material e inmaterial de la civilización humana, y su cumulativo progreso económico, expreso por la suma del PIB anual de las naciones. Por lo tanto, aun que las mujeres han logrado importantes conquistas recientes en el ámbito de los derechos civiles y laborales es todavía imperioso reconocer que aún existe una deuda acumulada de milenios de injusticia para con las mujeres por la injustificable actual inexistencia del concepto de débito primal, bien como su reconocimiento internacional y consecuente establecimiento como un tema de extrema relevancia social a ser desarrollado en el ámbito de los derechos reproductivo de las mujeres. Así que, en este artículo, como una primera acción hacia el reconocimiento de esa deuda primitiva, es propuesta la introducción del concepto de débito primal en el ámbito de los derechos reproductivos de las mujeres; objetivando la futura institución de su debido resarcimiento monetario, por medio de efectivos mecanismos jurídicos a ser desarrollados por los órganos responsables por las políticas de defensa de los derechos de las mujeres en escala mundial.

Palabras claves: capital humano; derechos humanos; derecho reproductivo; derecho de las mujeres; patriarcado.

Cómo citar:

Castro-Domínguez, Gabriela. (2021). Débito primal: un nuevo concepto en el ámbito del derecho reproductivo de las mujeres. Revista de Investigaciones Universidad del Quindío, 33(S2), 125-131. https://doi.org/10.33975/riuq.vol33nS2.621

Revista de Investigaciones Universidad del Quindío, 33(S2), 125-131; 2021. 


\section{ABSTRACT:}

In this paper it is proposed the concept of primal debt in the context of the women reproductive rights. Such a concept unfolds from the critical analysis of the symbiotic relationships between patriarchy and capitalism and the way in which they have historically been involved in perjury and economic exploitation of women through their natural reproductive capacity. In fact, it is an unquestionable biological aspect that women constitute the primary and unique source of continuous human capital generation; main productive factor since always used for the construction of all the material and immaterial wealth of human civilization, and its cumulative economic progress, expressed by the sum of the annual GDP of the nations. Therefore, even though women have achieved important recent achievements in the context of civil and labor rights, it is nevertheless imperative to recognize that there is an accumulated deity of millennia of injustice to women because of the unjustifiable current inexistence of the concept of primal debt, as well as its international recognition and consequent establishment as a topic of extreme social relevance to be developed in the context of the reproductive rights of women. Since, in this work, as a first action for the recognition of this primitive idea, it proposes the introduction of the concept of primal debt in the context of the reproductive rights of women; aiming at the future institution of its due monetary reimbursement, by means of effective legal mechanisms to be developed by the organizations responsible for the policies of defense of the rights of women on a world scale.

Keywords: human capital; human rights; reproductive rights; women's rights; patriarchy.

\section{INTRODUCCIÓN}

Constituye una verdad biológica universal, por todos los aspectos naturales la absoluta relevancia de la innata capacidad reproductiva de las mujeres para el origen y posterior desenvolvimiento, supervivencia y evolución de la civilización humana desde sus orígenes primordiales, es decir primales. De hecho, las mujeres, como fuente natural de la vida humana y matrices generadoras de los más de 6 mil millones de individuos de la especie humana que habitan la tierra actualmente; bien como del incalculable sumatorio del capital humano que construyó la civilización humana a lo largo de milenios de la historia.

Así que sin sombra de duda es importante reconocer que las mujeres son las legítimas creadoras del continuo progreso económico, cultural, científico y material de la civilización, especialmente en los dos últimos siglos de la era industrial basada en valores patriarcales y sobre el dominio de la doctrina capitalista, donde para bien o mal, todas las actividades y creaciones humanas son de alguno modo monetizadas, es decir, hay uno costo a ser pago aunque ese pago sea la mayoría de las veces vilipendiado por la desigual relación entre capital versus trabajo

Así que en la concepción existe un débito nunca antes propuesto o reconocido (Mattar, 2008) de la civilización humana patriarcal y capitalista ante todas las mujeres y madres del mundo: las cuales desde siempre fueron y continúan a ser las responsables por la generación tras generación, hasta nuestros días, de todo el capital humano que ha pasado por el planeta, constituyendo así la suma material del proceso civilizatorio humano con todas su capacidades, creaciones, mano de obra utilizada y explotada, incluso también, las propias mujeres, a lo largo de la historia. 
Por lo tanto, nada más justo es que, con retardo de dos mil años, introduzcamos lo que aquí llámanos débito primal: sea el reconocimiento de esa deuda que remonta de los orígenes de la humanidad y que a nuestro conocimiento nunca ha sido siquiera inventada por los estudiosos en los ámbitos de los derechos humanos y laborales o más evidente en el ámbito de los derechos reproductivos de las mujeres, en los cuales estamos proponiendo el inmediato y justo reconocimiento en plano internacional.

En efecto, se considera pertinente dicha propuesta ya que al introducir el concepto del débito primal en el ramo de los derechos reproductivos de las mujeres también se reconoce su observancia e implementación sobre una forma de resarcimiento monetario a las mujeres por el factor reproductivo que indudablemente puede traer efectos económicos y sociales muy benéficos para la humanidad con inmensas consecuencias positivas para el tercer milenio. (mujeres felices niños felices, sociedad feliz) Esto dicho, la pregunta que nos queda es: ¿Cuál sería, entonces ante las mujeres del mundo el monto de la deuda que la sociedad humana, bajo cualquier régimen político o económico, tendría con las mujeres?

Si se contara en todos los países, a lo largo del tiempo, la contribución esencial de las mujer no sólo con la creación de seres humanos sino que también como la fracción humana que garantiza la subsistencia de este capital humano, a través de la dedicación total de este ser a través del cuidado, de educar, enseñar, alimentar y garantizar la seguridad y vida de todos los seres humanos durante su niñez y juventud hasta que ellos mismos sean absorbidos como mano de obra y captados para formar la inmensa masa de trabajo del proletariado que alimenta y mueve a todos los sectores y actividades económicas de los países (Rosas \& Gámez, 2016).

Este manifiesto tiene como principal objetivo protestar contra la explotación el saqueo y la expropiación atávica, perenne, irreparable, universal y verdaderamente asombrosa de la que las mujeres, desde siempre, han sido víctimas de manera planificada y persistente por la sociedad humana patriarcal y capitalista históricamente gobernada. por costumbres, leyes, reglas, convenciones y principio de carácter androcéntrico, institucionalizados a lo largo de milenios.

\section{METODOLOGÍA}

Para el acercamiento del estudio de este tema se realizó una revisión doctrinal con base al método documental. El cual antepone un problema social que emerge en situaciones jurídicas que deben ser estudiadas en todo su contexto y dimensiones.

\section{RESULTADOS}

\section{Concepto de débito primal}

La palabra primal, según su origen etimológico significa primero. De ella derivan palabras como presbiacusia, presbiopia, presbitério, primario, así como primero, primitivo, primario, principio: siempre con el significado de "lo que viene primero o antes de todo"; como es el caso del débito a que nos referimos en el título de este artículo.

Por otro lado, hay que dejar claro la relación que establecemos respectivamente entre acreedor y deudor que a nuestro ver existe entre las mujeres y la construcción de la civilización humana (Recasens, 
s.f.), está, representada por su soporte patriarcal y capitalista, con aporte de lucrativo. Los verdaderos deudores una vez que reciben lucros al explotar la reproductibilidad del capital humano, mano de obra, y masa de trabajo generadas por las mujeres.

Así tomando en cuenta que una relación de deuda no es más que una relación bilateral entre un acreedor y un deudor. Entre el beneficiario de la deuda, por un lado, y el que debe resarcirla por otro queda clara la relación propuesta.

Sin embargo, para que el débito exista de hecho y de derecho, $\mathrm{y}$, sea posible cobrarlo, el mismo debe ser reconocido con la plena aceptación del deudor y del beneficiario, mediante registro en dispositivo legal lo que entonces legítima, en caso de negación del deudor, el reclamo del mismo en la esfera judicial. Cabe resaltar que no necesariamente la naturaleza del débito, su observancia y rescate debe ser necesariamente material, aunque siempre puede traducirse en derechos pecuniarios, dependiendo del caso en análisis

Se observa que, en las acciones judiciales de las distintas áreas del derecho, al final siempre existirá, reconocida la legitimidad jurídica del débito, una rescate pecuniario o equivalente.

\section{Críticas al prima débito}

Puede ser que, al ser juzgada la cuestión de la deuda primaria aquí propuesta, ciertamente en una apreciación superficial del asunto argumentarán con la lógica del patriarcado que la capacidad de procrear es una condición innata y exclusiva de la mujer, un don divino bajo el cual ellas, las mujeres, no pueden reclamar el derecho a la compensación porque no pueden equipararla al trabajo (Organización Panamericana de la Salud, 2008).

Ahora su fundamento radica que, siendo un don divino, la capacidad de procrear de las hembras está presente en toda la naturaleza; en todas las especies y ninguna de ellas recibe ningún beneficio por esta capacidad; entre tanto ninguna de especies a excepción de la humana la capacidad reproductiva es monetizada y ni sirve como factor principal para generar riqueza.

Sin dejar a un lado que las mujeres son más sacrificadas que los hombres cuando se encargan no solo de los hijos sino también de cuidar, de proteger, de alimentar, enseñar lo básico para su supervivencia en medio de depredadores implacables (Micolta, 2008). Si bien algunos hombres también hacen esa función el porcentaje es mínimo por lo cual difiere mucho de las condiciones que se ofrecen a las hembras humanas. Pongamos el ejemplo más común; en relación al ámbito laboral en tanto el hombre puede ir a trabajar y tener todos los beneficios de ley la mujer por tener que cuidar a los hijos debe realizar trabajos informales, trabajos del que puedan obtener dinero sin salir de casa como vender comida, vender algún producto, lavar o limpiar ajeno, entre otros (Arias, 2016).

Es intolerante que no reconozcan el papel de una humana madre e incluso la equiparan a las especies animales féminas para minimizar y esconder que existe una gran diferencia. Sucede que la descendencia de otras especies no humanas no crea la llamada riqueza material que impulsa y desenvuelve el progreso económico, social y cultural como lo hace la descendencia humana. seres humanos generados por mujeres. Estos, una vez creados, educados y formados, servirán como masa de trabajo en todos los sectores de las actividades humanas. 


\section{El proceso civilizatorio como una empresa transnacional}

Considerando el proceso civilizatorio como una empresa transnacional que opera en escala global usando los recursos materiales del planeta como el indispensable capital humano (Rivero, 2009) generado por las mujeres, queda muy evidente que mediante su exclusiva y única capacidad reproductiva las mujeres son la fuente primaria de donde se origina todo el desarrollo de la gran empresa llamada civilización humana, sin que nunca tengan logrado hasta el presente momento cualquier beneficio o reconocimiento en razón expresamente de su indispensable actividad reproductiva, en verdad garantizadora de la propia existencia y supervivencia de nuestra civilización como un todo.

Sin embargo, en el mundo capitalista cuando se habla en empresa también se habla en lucros (González, 2005), dividendos y otros medios de participación de los cuales las mujeres como matrices del capital humano y del capitalismo, debido a la estructura patriarcal de esa gran empresa, jamás recibieron cualquier dividendo por su providencial participación.

Así que si elegimos solo como un ejemplo, en el ámbito de la justicia laboral, quedará claro que esa injustificable deshumanidad que se ha impuesto a las mujeres desde siempre si fuera analizada en un juzgado laboral seguro que sería considerada como una situación de explotación equivalente a un régimen de trabajo esclavo, casi como una versión adversa de la llamada ley de libertad de vientre (Rodríguez \& Martínez, 2012), es decir, sea una Ley del vientre esclavo exclusiva para las mujeres teniendo en cuenta que las niñas ya nacen de otras niñas en una especie de campo de concentración de un sistema esclavista construido para realimentar y mantener la continua generación, fabricación, del necesario capital humano, individuos humanos para mano de obras, los niños: y para reproducción, las niñas, como se hacen en las granjas designadas a la creación de animales. Así es para la formación de capital humano y consecuente generación de la riqueza, no de las naciones y si de algunos ciudadanos de estas naciones.

La creación que surge del capital humano (Peralta, 2016), como cultura, artes, deporte, en todas las actividades que realiza la masa del capital humano generado por mujeres, sería incalculable, pero podemos hacernos una idea de dividir el PIB mundial por el número de habitantes económicamente activos.

Si se tuviera que considerar a la humanidad y su desarrollo como una mega empresa capitalista, y contabilizar, monetizar, toda la masa de riqueza producida por los seres humanos durante siglos, sumemos todo y establezcamos una participación en las ganancias de este esfuerzo humano del capitalismo, ¿cómo? muchos por ciento encajarían a las mujeres como generadoras de capital humano en esta gran empresa transnacional llamada civilización humana.

\section{Las mujeres y el desarrollo económico}

En vista de su determinismo biológico, las mujeres, constituyen la única y exclusiva fuente natural para la reproducción de la vida humana; constituyendo así la matriz generadora universal de todos los seres humanos que llegaron a existir, que ahora existen o que existirán en el futuro de la humanidad. Esto nos lleva a considerar que la función de la mujer (Fajardo et al., 2005) ha estado universalmente presente como fundamento de toda producción de riqueza desde los tiempos inmemoriales de la civilización humana, aunque el concepto de capital humano surgió hace solo dos siglos con el inicio de la era industrial y solo hasta la edad moderna reconoció que el factor principal de la actividad industrial es el humano y no solamente los recursos materiales. 
Teniendo en cuenta los inmensos beneficios sociales en escala mundial al implementar un tipo pago directamente a las mujeres que son madres no hay justificación para no reconocer como una medida necesaria de emergencia prioritaria el derecho de débito primal.

Considere como ejemplo la actual pandemia mundial con sus trágicos efectos económicos sociales y sanitarios ¿cuál fue la medida emergente más relevante y eficaz tomada por los gobiernos de la mayoría de los países para disminuir la crisis humanitaria global? sin duda fue la ayuda a las mujeres a través de un pago económico por el cual es cierto que muchos millares de niños fueron salvos por tener garantizadas por lo menos su necesidad básica de alimentación para el enfrentamiento del covid19.

Hay que tener en cuenta que la implementación del débito primal y su efectiva implementación puede constituirse en la mejor acción de prevención contra futuros eventos de esta naturaleza y que si ya hubiera leyes en este objetivo quizá no tendríamos la inmensa cuantidad de muertos como tenemos en esta pandemia, principalmente considerando la realidad que en todo el mundo existen millones de madres con hasta dos niños solas sin ninguna especie de ayuda externa.

\section{Débito primal. Resarcimiento}

La importancia, desde todos los puntos de vista, del género femenino, por su capacidad reproductiva exclusiva y natural desde el principio de los tiempos, son la fuente de todo el capital humano, produciendo la verdadera materia prima para la construcción de la civilización y la sociedad (Novo, 2003). Y todo lo que se ha generado a partir de bienes y riqueza durante generaciones milenarias. Por lo tanto, es incuestionable el derecho de las mujeres al reembolso de los 6 billones de seres humanos que viven actualmente, así como de los incontables billones de seres humanos que pasaron por aquí, trabajaron, reprodujeron, generaron arte, ciencia, cultura, servicios, agricultura, en resumen, toda la compleja economía del mundo moderno.

Esta no es una tarea imposible para los macroeconomistas. Sumando los PIB de todos los países a lo largo de décadas y convirtiendo este total en moneda corriente, obtendríamos el valor per cápita de la producción de riqueza y, por lo tanto, en vista de la población mundial anual, en teoría sería posible calcular un pequeño porcentaje de esta suma para que se asignen a mujeres de todas las generaciones como participación en los beneficios de esta empresa humana cuyo objetivo es y ha sido siempre la construcción de la sociedad y la civilización humanas.

\section{DISCUSIÓN}

En este artículo fue propuesto el concepto del débito primal en el ámbito del derecho reproductivo de las mujeres. Tal concepto ha sido desarrollado con vistas a demonstrar la necesidad de reconocer, institucionalizar y resarcir la deuda milenar de la civilización humana frente a las mujeres por su contribución en la construcción del progreso y riqueza material de la humanidad mediante su capacidad reproductiva, o sea, la capacidad de generación de todo el capital humano utilizado en el proceso civilizatorio.

El objetivo es institucionalizar la adopción del concepto del débito primal de tal modo que su efectiva implementación sea responsabilidad de los gobiernos nacionales, sobre reglas de los órganos internacionales responsables por la defensa de los derechos de las mujeres, por medio de legislación específica para su accionamiento en el ámbito de los derechos humanos, derechos de las mujeres y 
en especial de los derechos reproductivos. Se presenta esta propuesta al estudio de los legisladores, economistas y políticos.

Por tanto, considerando las distintas áreas del derecho, es imperioso reconocer que las mujeres como fuente generadora de capital humano con su diversidad de facetas tienen derecho a la institución de una compensación económica limitada pero sustancial capaz de darse a sí misma una participación en revertir en la creación de mejores oportunidades para sus hijos y nietos, aumentando así los recursos necesarios para cada generación de educación y mejoramiento del capital humano para los desafíos del tercer milenio.

Así también como consecuencia de la introducción de este concepto puede mudar la constante lucha de los movimientos feministas por alcanzar la igualdad de género cuando en realidad se debe luchar por algo superior como es la primalidad. Se torna confuso querer una igualdad frente a los hombres cuando las mujeres están, por su naturaleza, en varios escalones por encima de ellos, ya que las mujeres son el centro de todo pues sin ellas no existirían los hombres ya que solo ellas tienen o deberían tener el derecho de llevar a cabo, o no la gestación completa de un humano.

\section{REFERENCIAS}

1. Arias, Patricia (2016). El trabajo femenino: del permiso a la obligación. Papeles de Población, 22(90),197-228.

2. Fajardo Caldera, $M^{a}$. Isabel, \& Bermejo García, $M^{a}$. Luisa, \& Ruiz Fernández, $M^{a}$ Isabel, \& Fajardo Caldera, $\mathrm{M}^{\mathrm{a}}$. Guadalupe (2005). La mujer y lo femenino en el mundo actual. International Journal of Developmental and Educational Psychology, 1(1),197-206.

3. González González, Humberto (2005). Economía y empresa. Semestre Económico, 8(15),117-135.

4. Mattar, Laura Davis. (2008). Reconocimiento jurídico de los derechos sexuales: un análisis comparativo con los derechos reproductivos. Sur. Revista Internacional de Direitos Humanos, 5(8), 60-83. https://doi.org/10.1590/S1806-64452008000100004

5. Micolta, Amparo (2008). Apuntes históricos de la paternidad y la maternidad. Prospectiva. Revista de Trabajo Social e intervención social, (13).

6. Novo, María (2003). La mujer como sujeto, ¿utopía o realidad? POLIS, Revista Latinoamericana, 2(6).

7. Organización Panamericana de la Salud. (2008). La economía invisible y las desigualdades de género. La importancia de medir y valorar el trabajo no remunerado. Washington.

8. Peralta Solorio, Ernesto Felipe. (2016). La Productividad de la Población Económicamente Activa (PEA) en México: Historia, Panorama Actual y Perspectiva. Diálogos en la Sociedad del Conocimiento, 4(10), 165-186.

9. Rodríguez-Yong, Camilo A, \& Martínez-Muñoz, Karol Ximena. (2012). El contrato de maternidad subrogada: La experiencia estadounidense. Revista de derecho (Valdivia), 25(2), 59-81. https:// dx.doi.org/10.4067/S0718-09502012000200003

10. Rosas Rojas, Eduardo \& Gámez Arroyo, Jessica. (2016). Capital humano: el factor de producción más relevante para el crecimiento económico de américa latina. Journal CIM, Vol. 4(1), 1-8.

11. Recanses Siches, Luis. (s.f.). Vida humana, sociedad y derecho. España.

12. Mesino Rivero, Ledis. (2009). La globalización económica y sus implicaciones socio- culturales en América Latina. Revista de Ciencias Sociales, 15(1), 126-138. 